\title{
Cooperative interactions between the central spindle and the contractile ring during D rosophila cytokinesis
}

\author{
Maria Grazia Giansanti, ${ }^{1}$ Silvia Bonaccorsi, ${ }^{1}$ Byron Williams, ${ }^{2}$ Erika V. Williams, ${ }^{2}$ \\ Carlo Santolamazza, ${ }^{1}$ Michad L. Goldberg, ${ }^{2}$ and Maurizio Gatti ${ }^{1,3}$

\begin{abstract}
${ }^{1}$ Istituto Pasteur-Fondazione Cenci Bolognetti, Dipartimento di Genetica e Biologia Molecolare, Universitá di Roma “La Sapienza," 00185 Rome, Italy; 'Section of Genetics and Development, Cornell U niversity,

Ithaca, N ew York 14853-2703 USA
\end{abstract}

We analyzed male meiosis in mutants of the chickadee (chic) locus, a Drosophila melanogaster gene that encodes profilin, a low molecular weight actin-binding protein that modulates F-actin polymerization. These mutants are severely defective in meiotic cytokinesis. During anatelophase of both meiotic divisions, they exhibit a central spindle less dense than wild type; certain chic al lelic combinations cause almost complete disappearance of the central spindle. Moreover, chic mutant spermatocytes fail to form an actomyosin contractile ring. To further investigate the relationships between the central spindle and the contractile ring we examined meiosis in the cytokinesis-defective mutants KLP3A and diaphanous and in testes treated with cytochalasin B. In all cases, we found that the central spindle and the contractile ring in meiotic anatelophases were simultaneously absent. Together, these results suggest a cooperative interaction between elements of the actin-based contractile ring and the central spindle microtubules: When one of these structures is disrupted, the proper assembly of the other is also affected. In addition to effects on the central spindle and the cytokinetic apparatus, we observed another consequence of chic mutations: A large fraction of chic spermatocytes exhibit abnomal positioning and delayed migration of asters to the cell poles. A similar phenotype was seen in testes treated with cytochalasin B and has been noted previously in mutants at the tw instar locus, a gene that encodes a D rosophila member of the cofilin/ADF family of actin-severing proteins. These observations all indicate that proper actin assembly is necessary for centrosome separation and migration.

[Key Words: chickadee mutations; cytokinesis; central spindle; contractile ring; profilin; Drosophila]

Received July 16, 1997; revised version accepted N ovember 14, 1997.

In animal cells, cytokinesis is accomplished by the contractile ring, a transient structure containing actin and myosin II filaments that is anchored to the equatorial cortex. Interactions between these filaments lead to the constriction of the ring, which pinches the dividing cell in the middle like a purse string until cleavage is completed (for review, see Satterwhite and Pollard 1992; Fishkind and Wang 1995; Goldberg et al. 1997).

$M$ any experiments have clearly shown that the spindle controls the occurrence and positioning of the cytokinetic event (e.g., Hiramoto 1956, 1971; Hamaguchi 1975; Rappaport 1986, 1991). In large echinoderm eggs that contain prominent asters and a small central spindle/ spindle midzone (two names for the bundle of interdigitated microtubules between the separating chromosome complements during anaphase and tel ophase), the stimu-

${ }^{3}$ Corresponding author.

E-MAIL gatti@axcasp.caspur.it; FAX 39-6-4456866.
Ius for assembly of the contractile ring is provided primarily by the asters. This was elegantly shown by Rappaport (1961), who mani pulated sand doll ar eggs containing two spindles into a horseshoe shape. In these eggs, cytokinesis occurred not only in the canonical positions equidistant between the two asters of each spindle, but also between the asters of different spindles. Further evidence for a key role of asters in signaling cytokinesis was obtained by selective removal of different parts of the spindle from sea urchin eggs (Hiramoto 1971). Other micromanipulation experiments on echinoderm eggs, however, have shown that the central spindle can also play an important role in promoting cleavage furrow formation (Rappaport and Rappaport 1974, 1983; Rappaport 1985).

In animal cells that contain small asters and a relativel y large central spindle, the stimulus for cytokinesis appears to be provided primarily by the central spindle. Experiments on grasshopper neuroblasts showed that when the spindle is dislocated from its normal position 
by micromanipulation, the midzone of the repositioned spindle has the ability to stimulate cleavage (Kawamura 1977). This relationship may also extend to vertebrate eggs: Miller et al . (1993) noticed that when cytokinesis of Xenopus eggs was perturbed by calcium buffer injection, the location of the reforming furrow was dependent on the position of the central spindle rather than the poles. A strong correlation between the spindle midzone and the cleavage plane has also been shown by examination of multipolar mitotic figures in living rat kidney cells (Wheatley and Wang 1996) and in cultured human cells (Eckley et al. 1997). Moreover, modifications of the spindle midzone microtubules by either nocodazole or taxol result in specific and opposite effects on the organization of actin filaments in the cleavage furrow (Fishkind et al. 1996). Finally, Cao and Wang (1996) have recently obtained direct evidence that the central spindle of rat kidney cells provides the signals that stimulate cytokinesis. By puncturing these cells with a blunted needle, they created perforation barriers between different regions of the spindle and the cortex. Only barriers between the spindle midzone and the cortex suppressed cleavage in the equatorial region facing the perforation. Interestingly, whereas the interzonal microtubules were properly organized in the cleaving region of these cells, they were completely disorganized in the noncleaving part of the cells, suggesting an interaction between central spindle microtubules and the equatorial cortex (Cao and Wang 1996).

Our approach to elucidate the mechanisms underlying cytokinesis in animal cells is the identification and molecular characterization of genes that control this process in Drosophila melanogaster. Drosophila not only offers well-known advantages for genetic analysis, but also provides unique opportunities for cytologi cal examination of mutant phenotypes in different cell types (for review, see Giansanti et al. 1996). A Drosophila cell system that is highly suitable for phenotypic characterization of mutants defective in cytokinesis is male mei osis (Cenci et al. 1994; Gunsalus et al. 1995; Williams et al. 1995; Giansanti et al. 1996). The existence of cytokinesis problems in mutant testes is readily apparent through effects on the easily recognized products of meiosis, the spermatids (see below). Moreover, cytokinesis defects can be analyzed with exquisite cytological resolution because of the large size of the spermatocytes. The mei otic spindles of Drosophila males are correspondingly large and exhibit a prominent central spindle that is pinched in the middle during cytokinesis (Cenci et al. 1994); these cells also exhibit an actin-based contractile ring around the spindle midzone where pinching occurs (Gunsalus et al. 1995).

In this paper we report that mutations in the chickadee (chic) locus disrupt cytokinesis during male meiosis, preventing the formation of both the central spindle and the contractile ring. The chic gene encodes a D rosophila profilin, a low molecular weight actin-binding protein that regulates actin polymerization (Cooley et al. 1992). In addition, we observed a simultaneous disruption of both the central spindle and the contractile ring in mu- tants at the diaphanous (dia) (Castrillon and Wasserman 1994) and KLP3A (Williams et al. 1995) loci, and in meiotic cells treated with cytochalasin B. Together, these results strongly suggest that during Drosophila male meiosis there is a cooperative interaction between the central spindle microtubules and elements of the actomyosin contractile ring, so that impairment of either of these structures prevents the formation of the other.

\section{Results}

Mutations at the chic locus

To isolate mutations affecting meiotic cell division in Drosophila males, we used P-element mutagenesis to generate a collection of autosomal male sterile mutants, and screened these stocks for defects in oni on stage spermatids (for the mutagenesis scheme, see Gatti and Goldberg 1991). The morphology of these cells, which consist of a nucleus associated with a mitochondrial derivative called the N ebenkern, is diagnostic of errors in chromosome segregation and/or cytokinesis that occurred during the previous mei otic divisions (Gonzal ez et al. 1989; Fuller 1993). We isol ated four mutations associated with aberrations in onion-stage spermatids that were suggestive of defects in meiotic cytokinesis (see below). All four mutations were mapped by in situ hybridization to the 26A interval in polytene chromosomes (data not shown). Transposase-generated precise excisions of the marked $P$ elements in these strains reverted the male sterility and the defective spermatid phenotype, indicating that the $P$ element was indeed the cause of the aberrant phenotypes. All four mutations failed to complement Df(2L)GpdhA (which removes bands 25D7-E1 to 26A8-9) for both male sterility and the aberrant meiotic phenotype, but complemented $\mathrm{Df}(2 \mathrm{~L}) \mathrm{clot} 7$ (which removes bands 25D5-6 to 26A 7). These findings prompted us to perform complementation tests between these mutations and previously described mutations in the chic locus a hot spot for P-el ement mutagenesis mapping to the same chromosomal interval (Cooley et al. 1992). All four mutations were allelic to each other and behaved as alleles of chic (Table 1); we refer to these subsequently as chic $^{R 1}$, chic $^{8 \mathrm{~A}}$, chic $^{13 E}$, and chic $^{35 \mathrm{~A}}$. This conclusion was verified by examining DNA adjacent to the site of Pelement insertion in each of these four mutant strains (see $M$ aterials and M ethods for details). The four P-element insertions were found within the chic gene (Fig. 1).

The male sterile chic al leles we recovered are not null mutations. Verheyen and Cooley (1994) have shown that chic is an essential gene; deletions of the coding region cause recessi ve embryonic lethal ity, whereas less severe alleles affect fertility in mal es and femal es and al so cause bending and kinking of adult bristles. The gene produces two major transcripts, both of which can encode the chic gene product: a constitutively synthesized 1.2-kb RN A and a 1.0-kb RN A specific to ovaries in femal es and probably to the germ line in males (Cooley et al. 1992). The four P-element insertions we obtained are clustered within $100 \mathrm{bp}$ of the first intronic region for the $1.0-\mathrm{kb}$ 
Table 1. Complementation analysis among chic mutant alleles

\begin{tabular}{|c|c|c|c|c|c|c|}
\hline $\boldsymbol{R} 1$ & Fs $M S A B$ & & & & & \\
\hline $8 A$ & Fs $M S A B$ & Fs $M S A B$ & & & & \\
\hline $13 E$ & Fs $M S A B$ & $F F M S A B$ & $F S M S A B$ & & & \\
\hline $35 \mathrm{~A}$ & FS MS NB & $F F M S A B$ & $F S M S N B$ & FS MS NB & & \\
\hline 37 & $F S M S A B$ & $F S M S A B$ & $F S M S A B$ & $F S M S A B$ & $F S M S A B$ & \\
\hline 1320 & Fs $M S A B$ & $F F M S A B$ & $F S M S A B$ & $F S M S N B$ & $F S M S A B$ & $F S M S A B$ \\
\hline \multirow[t]{2}{*}{$D f G p d h A$} & $F S M S A B$ & $F S M S A B$ & $F S M S A B$ & $F S M S A B$ & $S L A B$ & $F S M S A B$ \\
\hline & $\boldsymbol{R} I$ & $8 \mathrm{~A}$ & $13 E$ & $35 \mathrm{~A}$ & 37 & 1320 \\
\hline
\end{tabular}

(FF) Female fertile; (Fs) female semisterile, 2\%-5\% wild type fertility; (FS) female sterile; (MS) male sterile; (SL) semilethal; (NB) normal bristles; $(A B)$ abnormal bristles. $N$ ote that escapers from semilethal mutant combinations are sterile in both sexes.

transcript (Fig. 1). Cooley et al. (1992) have shown that other sterile mutations caused by P-element insertions within or very close to the same region (chic ${ }^{\text {neo }}$, chic $^{1320}$, and $\mathrm{chi}^{9951}$ ) abolish the 1.0-kb transcript, but still produce at least some of the $1.2-\mathrm{kb}$ chic mRNA from the constitutive promoter (see Fig. 1). Though we have no direct evidence, we anticipate that the four mutations we isolated affect expression of the chic locus in a simiIar manner. The phenotypic effects of all of these mutations on viability, male fertility, female fertility, and bristle morphology as homozygotes or as hemizygotes [over the del etion $\operatorname{Df}(2 \mathrm{~L}) \mathrm{G}$ pdhA ] are similar, as reported in Table 1. Relatively modest variations between the phenotypes associated with these alleles (Table 1) are likely to result from small differences in the amount of chic protein expressed in specific germ-line cells or in bristle-producing trichogen cells at specific times during development.

Mutations in chic block cytokinesis during male meiosis

As mentioned above, our interest in chic was originally sparked by aberrations in spermatid morphology in mutant testes that suggested difficulties in meiotic cytokinesis. These abnormalities are immediately obvious because of the characteristic appearance of spermatids directly after their formation at the so-called oni on stage. Wild-type oni on stage spermatids contain a single phaselight nucleus and a similarly sized phase-dark Nebenkern (Fig. 2A). The uni formity of nuclear and $\mathrm{N}$ ebenkern sizes in these spermatids is assured by cell behavior during cytokinesis. During the two meiotic divisions, mito- chondria are arrayed along the central spindle and are equally partitioned between the two daughter cells when the central spindle is pinched in the middle during cytokinesis (Fuller 1993; Cenci et al. 1994). Thus, failures in cytokinesis result in abnormally large $\mathrm{N}$ ebenkern associated with multiple normal-sized nuclei (Fuller 1993; Castrillon and Wasserman 1994; Gunsalus et al. 1995; Williams et al. 1995).

In testes of males either homozygous for a variety of chic alleles or heterozygous for various combinations of alleles or del etions of the locus, a large fraction ( $>90 \%$ in the strongest allel es) of onion-stage spermatids contain a single N ebenkern of larger than normal size, associated with two or more normal-sized nuclei (Fig. 2B; Table 2). A substantial proportion have two nuclei with an intermediate-size N ebekern, but most frequently, these aberrant spermatids contain four nuclei and a very large $\mathrm{Ne}$ benkern ( $T$ able 2). These phenotypes reflect failures of cytokinesis at either one or both meiotic divisions, respectively, which would prevent proper subdivision of mitochondria and nuclei into daughter spermatids. A smaller number of mutant spermatids have three nuclei; as explained by Gunsal us et al. (1995), these could result from secondary consequences of a failure in cytokinesis I. Yet, smal ler percentages of abnormal spermatids have more than four nuclei, indicating cytokinesis failures in both premeiotic gonial divisions and meiotic divisions. The occurrence of some failures in gonial cytokinesis is further suggested by the finding that in chic $^{35 \mathrm{~A}} \sim 3 \%$ of primary spermatocytes are polyploid (data not shown). Rarely, and especially in the strongest al lele, chic ${ }^{35 A}$, we observed spermatids with irregularly sized nuclei (T able 2 ), indicative of occasional errors in meiotic chromosome segregation. 

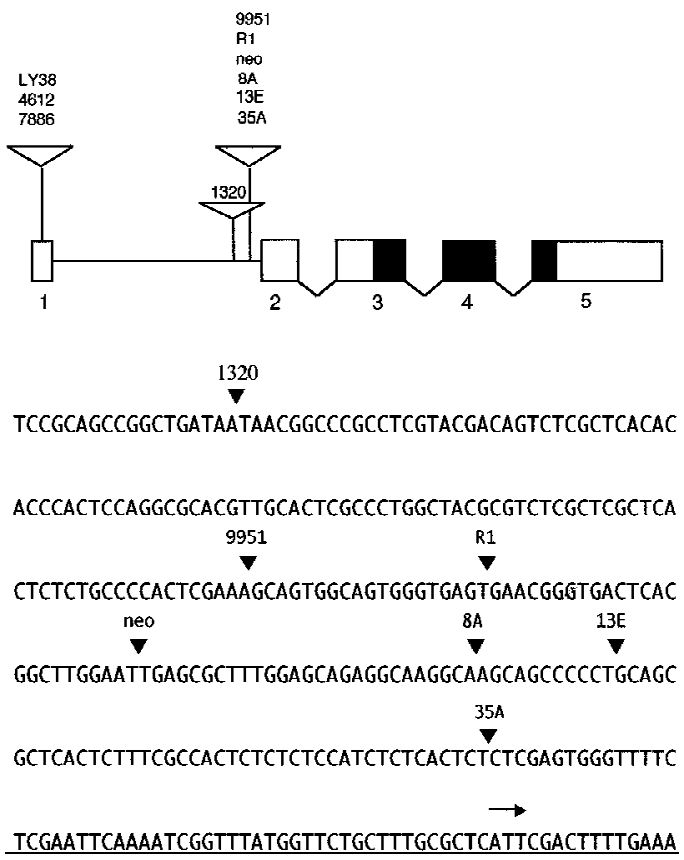

Figure 1. Map and partial sequence of the chic locus. (Top) $M$ ap of chic indicating the exon/intron organization and the positions of P-element insertions associated with chic mutations. This map is redrawn from Cooley et al. (1992) and Verheyen et al. (1994). The chic transcription unit produces two mRNAs: one of $1.0 \mathrm{~kb}$ that includes exons 1, 3, 4, and 5; and another of $1.2 \mathrm{~kb}$ comprised of exons 2, 3, 4, and 5. (Open boxes) Exons that do not encode parts of the chic protein; (solid boxes) protein-coding exons. The first intron is in scale with respect to the exons, whereas the other introns are not in scale. (Large, open inverted triangl es) Locations of P-el ement insertions. (Bottom) Partial DNA sequence of the first intron showing the position of the P-element insertions $(\boldsymbol{\nabla})$ associated with chic mutations. The locations of the insertions associated with 1320 , 9951, and neo have been determined by the laboratory of Dr. Lynn Cooley (pers. comm.). The locations of the R1, 8A, 13E, and 35A insertions have been determined in the present study (see Materials and Methods for details). The horizontal arrow indicates the start site of exon 2.

Mutations in chic disrupt contractile ring assembly and central spindle formation

To identify the primary defect that impairs meiotic cytokinesis in chic males, we analyzed mutant testes stained with anti-tubulin antibodies, rhodamine-conjugated phalloidin, and Hoechst 33258. This procedure allows simultaneous detection of microtubules, F-actin, and chromatin. In wild-type testes, phalloidin staining reveals an F-actin-enriched contractile ring that encircles the spindle midzone from late anaphase through telophase of both meiotic divisions (Fig. 3A; Gunsalus et al. 1995). In contrast, in $60 \%$ of chic ${ }^{13 E}$ ana-telophases I and II, and in $>95 \%$ of the ana-telophases I and II of the strongest chic mutants $\left(\mathrm{chic}^{\mathrm{RI}}, \mathrm{chic}^{8 \mathrm{~A}}, \mathrm{chic}^{35 \mathrm{~A}}\right.$ ), no actin staining was visible at the cell equator (Fig. 3C,D). M oreover, in most mutant ana-telophases with equatorial ac- tin staining, only irregular patches of F-actin were observed (Fig. 3B).

In addition to the absence of the contractile ring, the ana-telophases of all the chic mutants exhibit another obvious abnormality: a defect in central spindle morphology. In wild-type ana-tel ophases of both meiotic divisions, the two daughter nuclei are connected by a prominent bundle of interdigitating microtubules (Figs. $3 \mathrm{~A}$ and $4 \mathrm{~A}, \mathrm{~B}$; Cenci et al. 1994). In chic mutants, this central spindl e structure is considerably less dense than in wild type, and microtubules show very little or no interdigitation (Figs. 3C,D and $4 C, D$ ). In wild type, the central spindle is already evident by mid-anaphase, before the actin ring constriction has caused substantial equatorial pinching (Fig. 4A,B; Cenci et al. 1994). In the strongest chic mutants, we never observed these early stages of central spindle formation (Fig. 4), indicating that the chic phenotype reflects a failure of central spindle assembly rather than a degradation of this structure in the absence of the actin ring. Interestingly, we found a strong positive correlation between the presence of the contractile ring and the density of central spindle microtubules. In all the cases in which there was some actin staining at the cell equator, the density of central spindle microtubules was higher than that observed in cells completely devoid of an actin ring (Fig. 3B). Together, these observations indicate that chic mutations disrupt two major cytokinetic structures: the microtubule-based central spindle and the actomyosin contractile ring.

Profilin accumulates at the equator of meiotic ana-telophases

The fact that chic mutations have such strong effects on both of the major structures present at the equator of meiotic ana-tel ophases I and II, suggested to us the possibility that Drosophila profilin, the product of this gene,

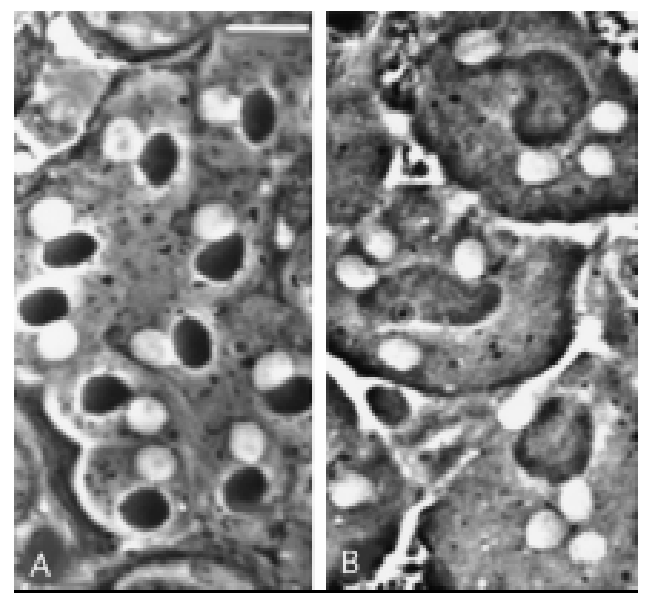

Figure 2. Abnormal spermatids in chic mutants. Live testes were examined by phase-contrast microscopy to determine spermatid defects in onion-stage cysts. (A) Wild-type spermatids showing nuclei and N ebenkern of similar sizes; (B) spermatids of $\mathrm{chic}^{\mathrm{R} 1}$ males with large N ebenkern associated with four nuclei of regular size. Bar, $10 \mu \mathrm{m}$. 
Table 2. Abnormal spermatids in chic mutants

\begin{tabular}{|c|c|c|c|c|c|c|c|c|c|c|c|c|}
\hline \multirow[b]{2}{*}{ Genotype $^{a}$} & \multirow{2}{*}{$\begin{array}{l}\text { N umber of } \\
\text { spermatids }\end{array}$} & \multicolumn{10}{|c|}{ Percent spermatids ${ }^{b}$} & \multirow{2}{*}{$\begin{array}{c}\text { Percent } \\
\text { abnormal }\end{array}$} \\
\hline & & $1: 1$ & $2: 1$ & $3: 1$ & $4: 1$ & $5: 1$ & $6: 1$ & $7: 1$ & $8: 1$ & $>8: 1$ & irr & \\
\hline Oregon-R & 500 & 100 & 0 & 0 & 0 & 0 & 0 & 0 & 0 & 0 & 0 & 0 \\
\hline $\mathrm{R} 1 / \mathrm{R} 1$ & 622 & 17.6 & 25.3 & 5 & 49.2 & 0.6 & 1.1 & 0.1 & 0.8 & 0.3 & 0 & 82.4 \\
\hline $8 \mathrm{~A} / 8 \mathrm{~A}$ & 688 & 8.8 & 15.5 & 5.6 & 61.4 & 1.2 & 2.9 & 0.3 & 1.2 & 1.2 & 1.9 & 91.2 \\
\hline 13E/13E & 448 & 58.7 & 23.2 & 4.7 & 10.5 & 0.4 & 0.2 & 0 & 0.6 & 0.4 & 1.3 & 41.3 \\
\hline $35 \mathrm{~A} / 35 \mathrm{~A}$ & 714 & 6.6 & 10.5 & 7.5 & 57.4 & 1.8 & 3.9 & 2.0 & 4.9 & 1.2 & 4.2 & 93.4 \\
\hline $37 / 37$ & 142 & 2.3 & 9.7 & 4.4 & 65.4 & 0.7 & 5.1 & 2.2 & 10.2 & 0 & 0 & 97.7 \\
\hline $37 / R 1$ & 69 & 1.4 & 18.0 & 2.9 & 67.6 & 2.9 & 2.9 & 0 & 1.4 & 2.9 & 0 & 98.6 \\
\hline 1320/R1 & 168 & 0.6 & 28.0 & 0.6 & 64.3 & 0 & 3.5 & 0 & 1.2 & 0.6 & 1.2 & 99.4 \\
\hline $1320 / 8 \mathrm{~A}$ & 273 & 4.4 & 16.8 & 5.5 & 65.0 & 0 & 1.8 & 0 & 5.8 & 0.7 & 0 & 95.6 \\
\hline
\end{tabular}

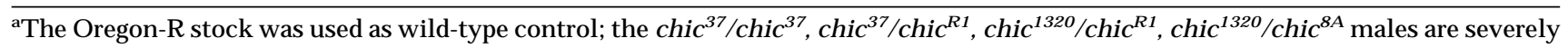
defective in germ-line cell proliferation.

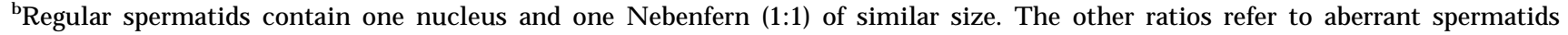
contai ning one abnormal ly large $\mathrm{N}$ ebenkern associated with multiple nuclei. The irregular class (irr) refers to spermatids with multiple nuclei containing at least one nucleus of irregular size.

might, in fact, be concentrated in the same region of dividing spermatocytes. Staining of fixed testes with an antibody directed against the chic protein (Verheyen and Cooley 1994) shows this supposition to be true. Profilin is distributed in a fairly diffuse pattern, but clear concentrations are observed near the cell cortex, particularly in the equatorial zone (Fig. 5). In the strongest chic mutants $\left(\mathrm{chic}^{\mathrm{R} 1}{ } \mathrm{chic}^{8 \mathrm{~A}}\right.$, chic ${ }^{35 \mathrm{~A}}$ ), profilin immunostaining is considerably weaker than in wild type, and profilin does not accumulate at the cell equator (Fig. 5).

Mutations in chic produce abnormal accumulations of F-actin

In addition to preventing contractile ring formation, chic mutations disrupt at least one more aspect of actin cytoskeleton dynamics, as they elicit the formation of F-actin aggregates that are not seen in wild-type testis cells. Abnormal aggregations of F-actin in chic mutants are observed primarily in premei otic mature spermatocytes at the S5 stage (Fig. 6C; for designations of the stages of Drosophila spermatogenesis, see Cenci et al. 1994). In the strongest chic mutants and in hemizygous individuals (mutant/Df), these aggregates persist until prometaphase I (stages M 1 and M 2) and then disintegrate.

We believe that these actin clusters represent remnants of the fusome, a structure that traverses the ring canals of male and female germ-line cells, connecting all the cells present in any given cyst (Lin et al. 1994; Gunsalus et al. 1995; Hime et al. 1996; Robinson and Cooley 1996). Although the male and female fusomes appear to have similar properties, they differ in their molecular composition. They both contain $\alpha$-spectrin, but the male fusome, in contrast to its femal e counterpart, is highly enriched in F-actin (Gunsalus et al. 1995; Hime et al. 1996). In wild-type males, the fusome connects the 16 primary spermatocytes during the early stages of their growth, but regresses in mature spermatocytes (stage S5), which only exhibit small fusome fragments (Gunsalus et
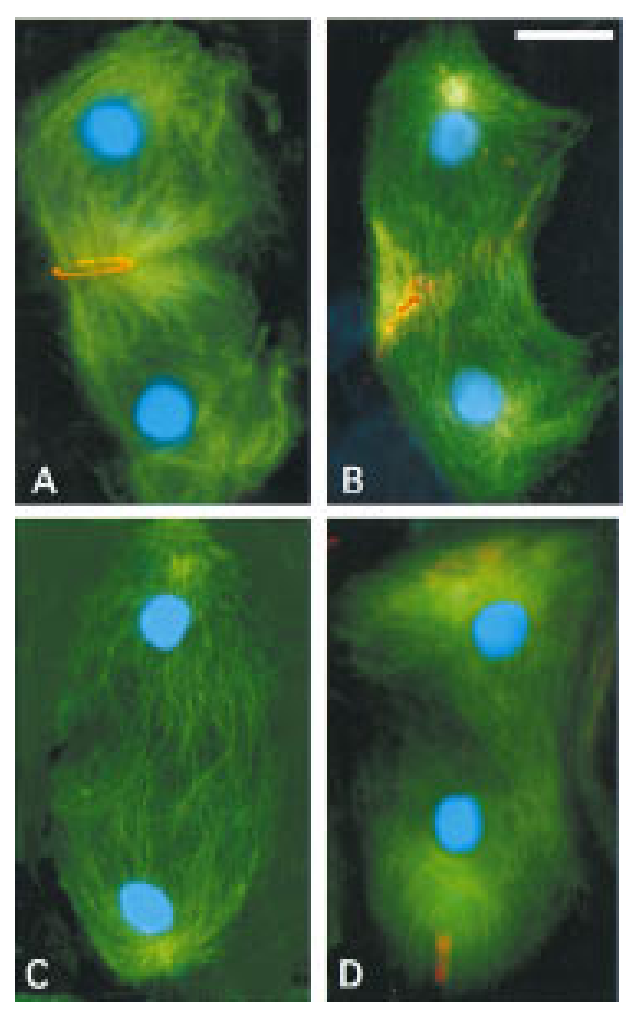

Figure 3. Defects in central spindle formation and contractile ring assembly during the first meiotic division in chic mutant males. Tel ophases from wild-type controls (A), chic ${ }^{13 E}$ mutants $(B)$, chic ${ }^{35 A}$ mutants $(C)$, and chic $^{R 1}$ mutants (D). Cells were sequentially stained with anti-tubulin antibodies and rhodamine-phalloidin to detect tubulin (green) and F-actin (red); they were then stained with Hoechst 33258 to visualize chromatin (blue). The fluorescent signals were recorded separately by a CCD camera and merged in pseudocolors. $N$ ote that the chic $^{35 \mathrm{~A}}$ and $\mathrm{chic}^{\mathrm{R} 1}$ telophases are severely defective in the central spindle and lack the actin-based contractile ring. In the chic $^{13 E}$ cell, the central spindle is irregular and less dense than in wild type; it exhibits only a patch of F-actin at the midzone (see text for further explanation). Bar, $10 \mu \mathrm{m}$. 

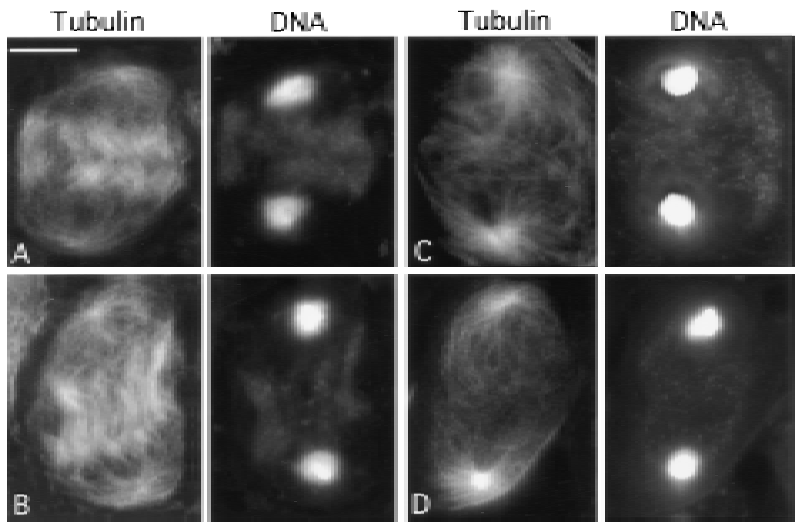

Figure 4. Failure of central spindle formation in chic mutants. (A,B) Wild-type mid-anaphases I showing microtubule interdigitation in the spindle midzone. $(C, D) \operatorname{chic}^{R 1}$ (C) and chic $^{35 \mathrm{~A}}$ (D) anaphases with a low density of noninterdigitating central spindle microtubules. Bar, $10 \mu \mathrm{m}$.

al. 1995). Although young chic spermatocytes have a normal fusome (Fig. 6A), the prominent F-actin-enriched aggregates in mature chic spermatocytes (stage S5) have the appearance of aberrantly long-lived fusome remnants (Fig. 6C,D). To test whether these actin structures were indeed fusome derivatives, chic testes immunostained with either an anti- $\alpha$-spectrin antibody or an anti-anillin antibody were sequentially stained with rhodaminephalloidin. Anillin has been shown previously to be a stable component of the mal e ring canals through which the fusome extends (Field and Alberts 1995; Hime et al. 1996). This analysis showed that the F-actin aggregates seen in chic S5 spermatocytes are enriched in $\alpha$-spectrin (Fig. 6D-F) and are almost invariably associated with ring canals (Fig. 6G-I). Together, these findings suggest that these actin aggregates are in fact relatively undegraded remnants of the male fusome.

\section{Mutations in chic affect aster migration}

In wild-type primary spermatocytes during the prophase-prometaphase transition of the first meiotic division (stage $\mathrm{M} 1$ ), centrosomes migrate from a position just under the plasma membrane to the nuclear envelope, where they nucleate prominent asters (T ates 1971; Cenci et al. 1994). The two asters then separate and move around the periphery of the nuclear membrane, so as to establish a bipolar spindle (Fig. 7A; Cenci et al. 1994). Similarly, during late tel ophase of the first meiotic division and the short interphase between meiosis I and meiosis II (stages M 5-M 6b), asters separate and migrate to the opposite poles of secondary spermatocytes (Fig. 7C; Cenci et al. 1994). In contrast, at the corresponding meiotic stages in chic mutants, the two asters often fail to separate from each other (Fig. 7D,F; T able 3). Furthermore, the asters in chic spermatocytes often fail to associate with the nucleus, remaining in ectopic po- sitions in the middle of the cytoplasm or near the plasma membrane (Fig. 7D,F).

Although the asters in chic mutants are improperly positioned by the start of prometaphase, relatively normal-looking bipolar spindles eventually form by late metaphase (Fig. 7E). It is remarkable that the function of these spindles, with respect to chromosome segregation, appears to be largely unimpai red, because we find only a very low frequency of onion-stage spermatids containing irregularly sized nuclei such as micronuclei (Table 2 ).

\section{chic is epistatic to twinstar}

Our previous investigations (Gunsalus et al. 1995) revealed that lesions in twinstar (tsr), a gene encoding a Drosophila cofilin (an actin severing and depolymerizing protein), cause a syndrome of phenotypic effects that have both similarities and differences to those described above for chic mutations. In tsr, as in chic spermatocytes, centrosome separation and migration are defective, abnormal accumulations of F-actin are apparent, and cytokinesis often fails after one or both meiotic divisions. tsr and chic mutant phenotypes, however, can be easily distinguished on the basis of several criteria. In tsr mutants, the central spindle is normal, and the contractile ring still forms (though in misshapen and enlarged form), in contrast to the situation for chic described above. Furthermore, as explained in the Discussion, the types of F-actin aggregates formed in tsr spermatocytes are much different from those in chic.

To further characterize the relationship between chic and tsr, we constructed flies simultaneously mutant for both $\operatorname{tsr}^{1}$ and $\mathrm{chic}^{\mathrm{R} 1}$. These double mutants die at the larval / pupal transition just as tsr $^{1}$ single mutants. Testes from larvae simultaneously homozygous for $\mathrm{chic}^{\mathrm{RI}}$ and $\mathrm{tsr}^{1}$, however, have a phenotype al most identical to that observed in $\mathrm{Chi}^{\mathrm{R}} \mathrm{C}^{\mathrm{s}}$ single mutants, indicating that chic is epistatic to tsr (Fig. 8). chic ${ }^{\mathrm{RI}} \mathrm{tsr}^{1}$ individuals show frequent defects in aster positioning and separation ( $>95 \%$ of the cells are affected), fail to form either a normal central spindle or an actomyosin contractile ring (in con-

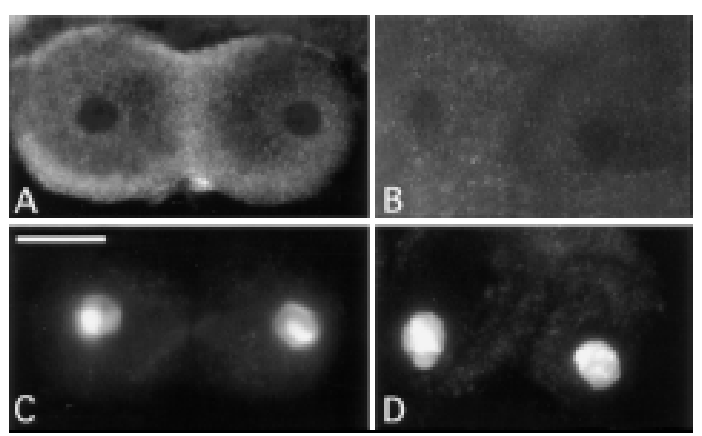

Figure 5. Localization of profilin during ana-tel ophase I of Drosophila male meiosis. (A,B) Immunostaining with anti-profilin antibody; (C,D) chromatin staining with Hoechst 33258. (A,C) Wild-type tel ophase I; $(B, D)$ chi $^{35 A}$ tel ophase I. $N$ ote that in the mutant, the overall intensity of profilin immunostaining is lower than in wild type; in addition, in the chic $^{35 \mathrm{~A}}$ cell there is no profilin accumulation at the cell equator. Bar, $10 \mu \mathrm{m}$. 

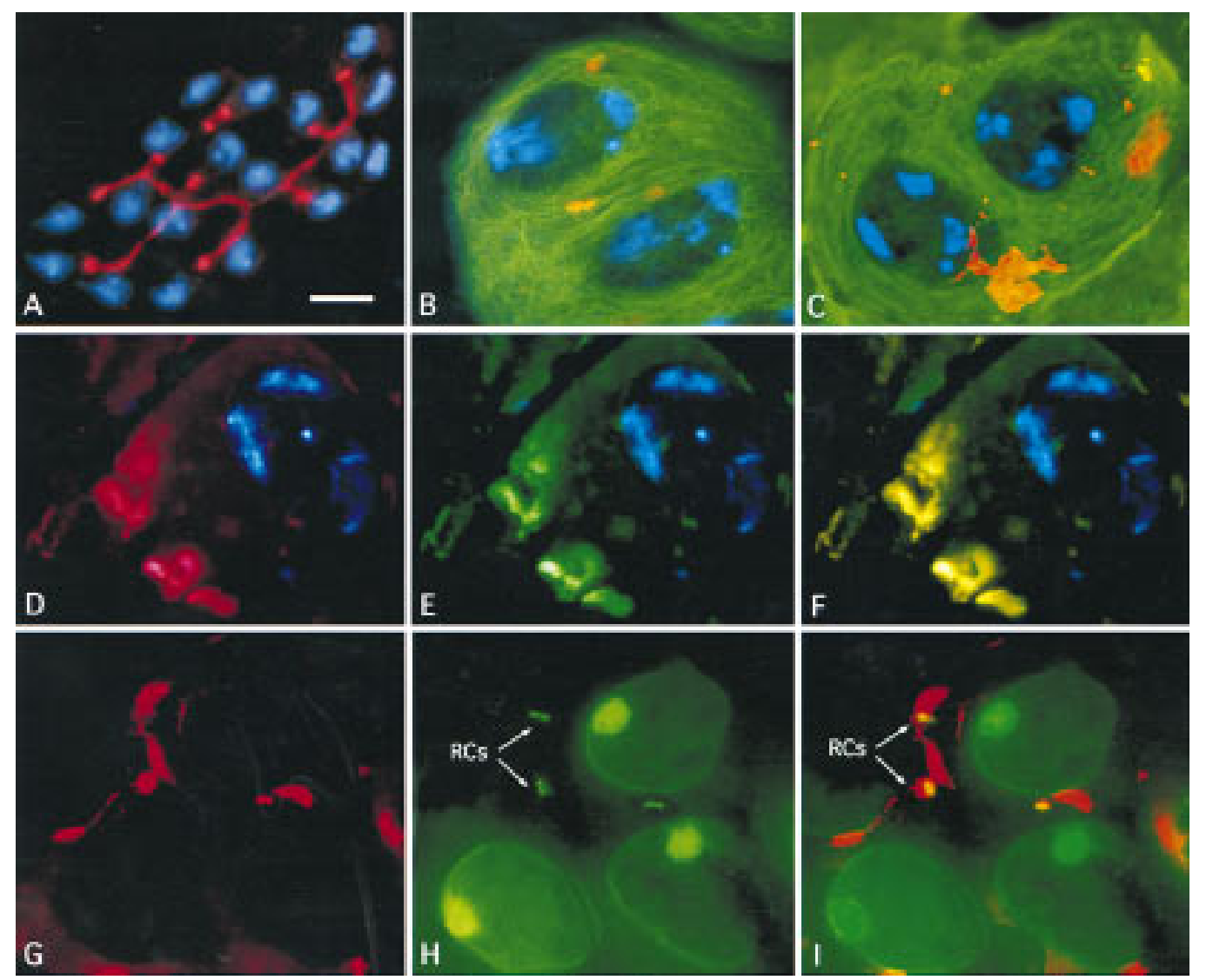

Figure 6. Actin behavior in chic mutants. To visual ize DN A and actin, larval testes were stained with Hoechst 33258 and rhodaminephalloidin. Tubulin, $\alpha$-spectrin and anillin were detected by immunostaining with specific antibodies. The fluorescent signals were recorded separately by a CCD camera and merged in pseudocolors. (A) Complete cyst from a chic $\mathrm{C}^{\mathrm{R}}$ mutant, including 16 young spermatocytes and two cyst cells (DNA in blue), that exhibits a normal actin-enriched fusome (red). Wild type (B) and chic ${ }^{\mathrm{R} 1}$ (C) premeiotic, mature primary spermatocytes at the S5 stage stained for chromatin (blue), tubulin (green), and F-actin (red); note the prominent F-actin aggregates present in the mutant. chic ${ }^{\mathrm{R} 1}$ primary spermatocyte at the S5 stage stained for chromatin (blue) plus $\mathrm{F}$-actin (red) in D, and for chromatin (blue) and $\alpha$-spectrin (green) in E; F is a merge of D and E showing colocalization of F-actin and $\alpha$-spectrin (overlap in yellow). chic $^{\mathrm{R} 1}$ primary spermatocytes at the S5 stage stained for actin (red, $\mathrm{G}$ ) and anillin (green, $\mathrm{H}$ ); (I) merge of $\mathrm{G}$ and $\mathrm{H}$. N ote that the ring canals (RCs, arrows) are traversed by the $\mathrm{F}$ actin-enriched fusome remnants. Bar, $10 \mu \mathrm{m}$.

trast with tsr), and exhibit many abnormal spermatids $(>95 \%)$ that contain a large Nebenkern associated with two or more nuclei. The actin aggregates present in mature $\mathrm{chic}^{\mathrm{R} 1} \mathrm{tsr}^{1}$ spermatocytes are similar in nature to those in $\mathrm{chic}^{\mathrm{R} 1}$ alone, but in the double mutant these actin masses are slightly larger and persist longer, until anaphase I (Fig. 8).

Relationship between the central spindle and the contractile ring

There is accumulating evidence that signals from the central spindle are requi red for proper organization of the actomyosin contractile ring (see introductory section). In this paper, we have shown that mutations in a gene encoding a Drosophila profilin disrupt not only contractile ring assembly, but also the organization of the ana-telophase central spindl e. One possi ble explanation for these findings is that signaling between these structures could work in both directions: Microtubules of the central spindle and the F-actin-based contractile ring may interact cooperatively at the cell equator. To test this hypothesis, we examined the effects on male meiosis of additional mutations or drug treatments that primarily disrupt either the microtubule or the actin cytoskeleton.

We have shown previously that the KLP3A gene encodes a kinesin-like protein that accumulates in the central spindle midzone during anaphase and telophase of both meiotic divisions. Accordingly, mutations in this gene disrupt central spindle formation and cause frequent failures in meiotic cytokinesis (Williams et al. 1995). To check whether the defect in central spindle integrity observed in KLP3A mutants al so affects actin ring assembly, we stained KLP3A ${ }^{\text {e4 }}$ mutant testes with rhodamine-label ed phall oidin. The results of this experiment clearly showed that most mutant ana-telophases 

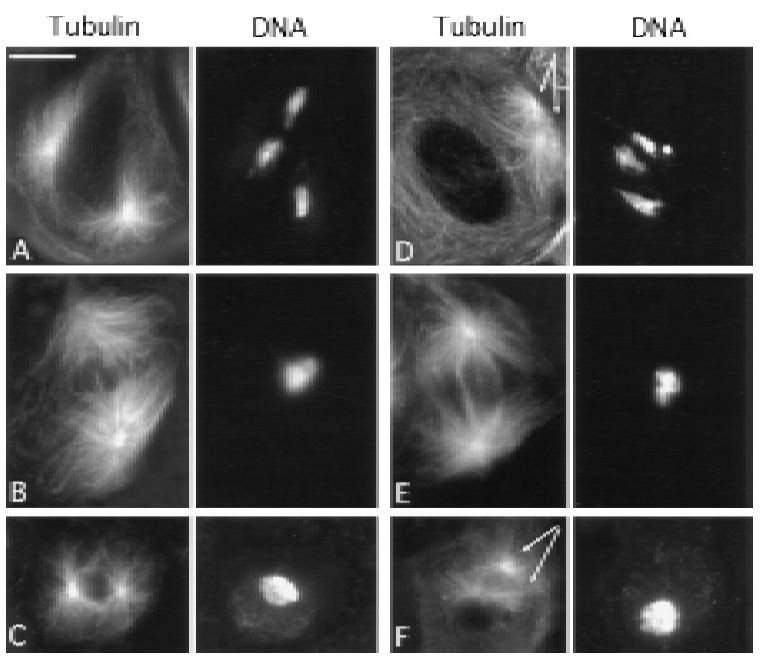

Figure 7. Abnormal aster positioning and migration in chic mutants. (A) Wild-type prometaphase at the M 1 stage of the first meiotic division; (B) wild-type metaphase I at the M 3 stage; (C) wild-type interphase secondary spermatocyte at the M 6b stage; (D) $\mathrm{chic}^{\mathrm{R} 1}$ prometaphase at the M 1 stage with ectopically positioned asters (arrows) that have failed to migrate to the cell poles. (E) chic ${ }^{\mathrm{R} 1}$ metaphase I at the M 3 stage; note that despite the delay in migration, the asters eventually attain a bipolar arrangement. ( $F$ ) $\mathrm{Chic}^{\mathrm{R} 1}$ secondary spermatocyte at the $\mathrm{M} 6 \mathrm{~b}$ stage with ectopic, unseparated asters (arrows). Bar, $10 \mu \mathrm{m}$.

(90\%) were completely devoid of actin rings (Fig. 9B). The rare ana-tel ophases that exhibited thin and incomplete actin rings also contained central spindles more dense than those of cells completely lacking contractile rings. Despite the absence of the contractile ring, KLP3A mutants did not exhibit aberrant actin accumulations or problems in aster migration like those described above for chic and tsr mutants.

The dia locus is required for cytokinesis during both neuroblast mitosis and male meiosis. The dia gene encodes a protein homologous to the products of the limb deformity gene of mouse and the BNI 1 gene of Saccharomyces cerevisiae (Castrillon and Wasserman 1994); dia also has a homolog in Schizosaccharomyces pombe (cdc12) needed for actin ring formation and cytokinesis. The $\mathrm{Cdc} 12$ protein colocalizes with the actin ring and interacts with profilin through its proline-rich domain (Chang et al. 1996, 1997). We thus tested whether dia is similarly involved in actin ring assembly during Drosophila male meiosis. All the ana-telophases present in testes homozygous for either the lethal allele $\mathrm{dia}^{3}$ or the male sterile allele dia ${ }^{1}$ were completely devoid of actin rings (Fig. 9C). It is of interest that these figures also showed severe defects in the central spindle, similar to those observed in chic and KLP3A: Central spindle microtubules were much less dense than in wild type and failed to interdigitate at the midzone (Fig. 9C). In addition, $50 \%$ of the meiosis I prometaphases in dia mutants exhibited ectopic positioning and delayed migration of asters (not shown).

The effects on the actomyosin contractile ring and the central spindle observed in chic and dia mutants could be specific consequences of lesions in the corresponding gene products. Alternatively, these effects could result from a more general di sruption of the actin cytoskel eton. To discriminate between these possibilities, we treated wild-type testes with cytochal asin B prior to fixation and staining (see Materials and Methods). Cytochalasin B binds the barbed ends of actin filaments and promotes the conversion of ATP-actin monomers to ADP-actin (Cooper 1987), preventing proper assembly of the contractile ring in most cell types (A ubin et al. 1981; Inoue 1990). Remarkably, incubation with this drug produced an almost exact phenocopy of strong chic alleles. No F-actin staining in any contractile ring-like structures at the equator of ana-tel ophase cells was observed (Fig. 9D). Importantly, cytochalasin B treatment also abolished microtubule interdigitation in the central spindle in anatelophase cells (Fig. 9D). Corresponding cytokinesis defects are indicated by a very high proportion (almost $100 \%$ ) of spermatids with enlarged N ebenkern and multi ple nuclei (Fig. 10C). In addition, disruption of the actin cytoskeleton with cytochalasin B produced ectopic asters in most prometaphase primary and secondary spermatocytes (stages $\mathrm{M} 1$ and $\mathrm{M} 6 \mathrm{~b} / \mathrm{M} 7$, respectively), indicating effects on centrosome migration and separation (Fig. 10A,B).

Table 3. Aster localization and migration during meiotic divisions in chic mutant males

\begin{tabular}{|c|c|c|c|c|c|c|}
\hline \multirow[b]{2}{*}{ Genotype $^{a}$} & \multicolumn{3}{|c|}{ Prometaphase I } & \multicolumn{3}{|c|}{ Prometaphase II } \\
\hline & normb & $\operatorname{irr}^{c}$ & $\%$ irr & norm ${ }^{b}$ & $\mathrm{irr}^{\mathrm{C}}$ & $\%$ irr \\
\hline Wild type & 158 & 10 & 5.9 & 232 & 10 & 4.1 \\
\hline $\mathrm{R} 1 / \mathrm{R} 1$ & 39 & 69 & 63.9 & 21 & 10 & 32.2 \\
\hline $8 \mathrm{~A} / 8 \mathrm{~A}$ & 11 & 36 & 76.6 & 32 & 21 & 39.6 \\
\hline $13 E / 13 E$ & 26 & 12 & 31.5 & 27 & 6 & 18.2 \\
\hline $35 A / 35 A$ & 24 & 36 & 60 & 53 & 11 & 17.2 \\
\hline $\mathrm{R} 1 / 37$ & 8 & 54 & 87 & 27 & 16 & 37.2 \\
\hline R1/1320 & 21 & 48 & 69.5 & 31 & 22 & 41.5 \\
\hline
\end{tabular}

The Oregon-R stock was used as wild-type control.

b(norm) N ormal aster localization and migration.

c(irr) Irregular positioning and delayed migration of asters. 

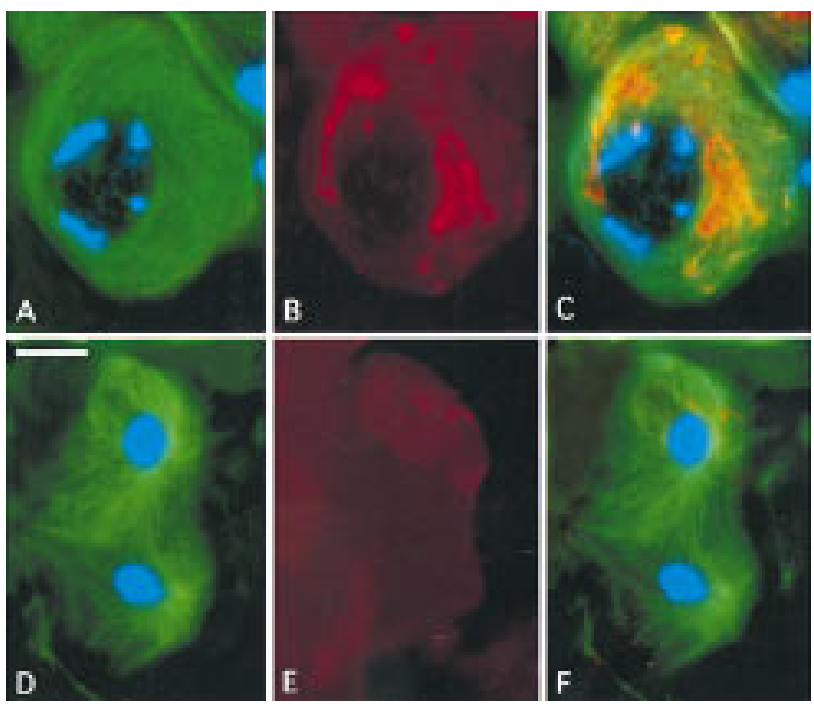

Figure 8. Actin and tubulin behavior in $\mathrm{chic}^{\mathrm{R} 1} \mathrm{tsr}^{1}$ double mutants. A premeiotic mature spermatocyte at the S5 stage (A-C) and a telophase I (D-F) stained for tubulin (green), chromatin (blue), and actin (red). Fluorescent signals were detected separately by a CCD camera as described previously. (C) M erge of $A$ and $\mathrm{B} ; \mathrm{F}$ is a merge of $\mathrm{D}$ and $\mathrm{E}$. Bar, $10 \mu \mathrm{m}$.

\section{Discussion}

Effects of chic mutations on F-actin-enriched structures

We have shown that mutations in the chic locus, which encodes a Drosophila profilin (Cooley et al. 1992), prevent the formation of the actin-based contractile ring and elicit the formation of actin aggregates that are not seen in wild type. Previously, we have observed abnormal actin accumulations in mutants at the tsr locus, a gene encoding a Drosophila cofilin (Gunsalus et al. 1995), but the abnormal actin structures observed in chic testes appear to have a different origin from those in tsr mutants. Mutations in tsr produce two types of abnormal actin aggregates. The first type forms near the centrosomes of each primary spermatocyte and rapidly grows within the cytoplasm during aster formation; this actin cluster persists through prometaphase and metaphase I and disintegrates during the first meiotic anaphase. The second type of actin aggregates seen in tsr mutants results from the failure to disassemble mei otic contractile rings. The abnormal F-actin masses derived from the contractile ring of the first meiotic cytokinesis di sintegrate only as late as the second meiotic anaphase, whereas the actin clusters originated from the second division rings persist in early spermatids, disintegrating slowly during spermatid el ongation. In contrast, the actin aggregates caused by chic mutations are observed primarily in mature spermatocytes at the S5 stage, are not associated with centrosomes, and disintegrate during the first meiotic division. These aggregates have the appearance of fusome remnants; this assignment is supported by the observations that they contain $\alpha$-spectrin and are almost al ways associated with ring canals. Because in wild-type mature spermatocytes at the $\mathrm{S} 5$ stage the fusome is al most completely disintegrated (Gunsal us et al. 1995), we suggest that degeneration of this structure is partially blocked in chic mutants, leading to the persistence of actin-enriched aggregates in S5 spermatocytes.

Our results clearly show that mutations in the chic locus suppress assembly of the contractile ring and disrupt meiotic cytokinesis. An involvement of chic in Drosophila cytokinesis was anticipated by Verheyen and Cooley (1994), who found binucleate nurse cells in mutant egg chambers. There is considerable precedent for the participation of profilin in cytokinesis of other organisms. Deletion of the profilin-encoding gene PFY1 disrupts cytokinesis in S. cerevisiae (Haarer et al. 1990). S. pombe with mutations in the profilin-encoding cdc3 gene do not form an actin ring and are defective in cytokinesis (Bal asubramanian et al. 1994). In Dictyostelium

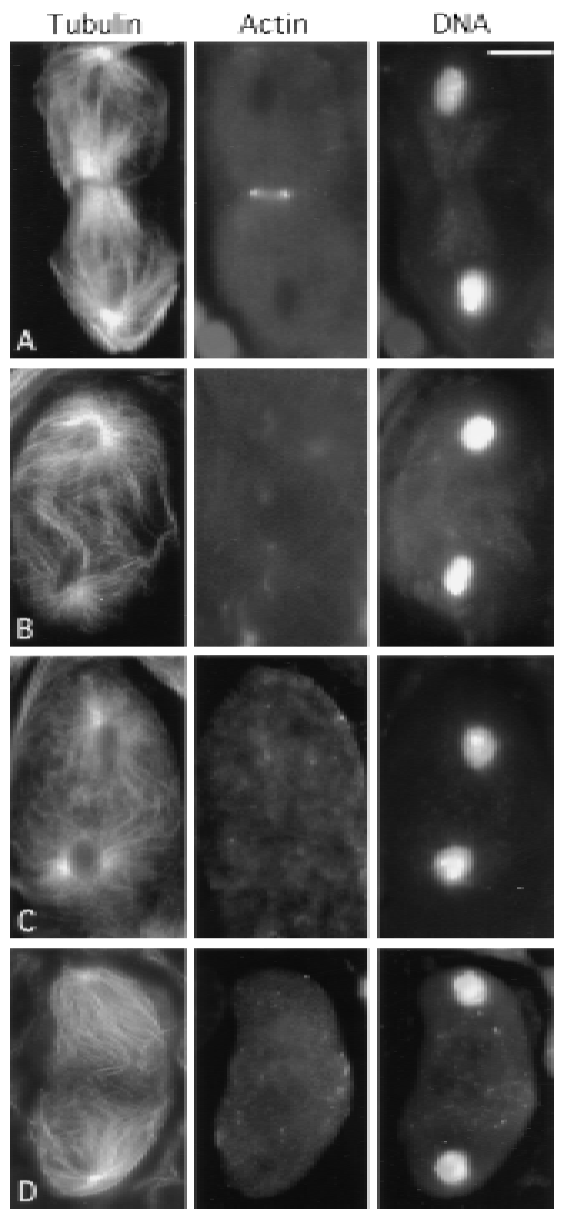

Figure 9. Effects of mutations in the KLP3A and dia loci, and of cytochal asin B treatment, on meiotic divisions in Drosophila males. (A) Wild-type control tel ophase I showing a regular actin ring around the central spindle midzone. Telophase I figures from KLP3A ${ }^{\mathrm{e}}(\mathrm{B}), \mathrm{dia}^{3}(\mathrm{C})$, and cytochalasin B-treated testes (D), all with severely defective central spindles and no actin rings. Bar, $10 \mu \mathrm{m}$. 


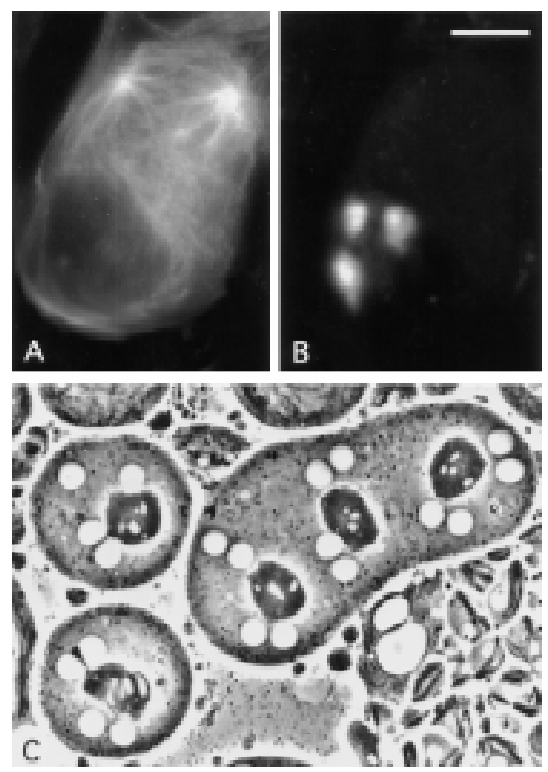

Figure 10. Effects of cytochalasin B on aster behavior and cytokinesis. A prometaphase I primary spermatocyte stained for tubulin (A) and chromatin (B), showing irregular aster positioning and migration. (C) Cytochal asin B-induced aberrant spermatids containing a large N ebenkern associated with four nuclei. Bar, $10 \mu \mathrm{m}$.

amoebae carrying mutations in both of their two profilin genes, cytokinesis is severely impaired, causing the formation of cells up to 10 times larger than wild type (Haugwitz et al. 1994). Finally, consistent with a role in assembly of the contractile ring, the $\mathrm{Cdc} 3$ profilin of $\mathrm{S}$. pombe concentrates in an equatorial band during mitotic cell division (Balasubramanian et al. 1994), and profilin is enriched in the cleavage furrow of Tetrahymena cells (Edamatsu et al. 1992). We have similarly observed here that the chic-encoded profilin accumulates at the equator of meiotic ana-telophases during Drosophila male meiosis.

Interestingly, in S. cerevisiae, S. pombe, and Dictyostelium, cells lacking profilin are not only defective in actin ring assembly and cytokinesis, but al so exhibit abnormal actin accumulations (Haarer et al. 1990; Balasubramanian et al. 1994; Haugwitz et al . 1994). Thus, both in these organisms and in Drosophila male mei osis, mutations in profilin genes inhibit F-actin polymerization in the contractile ring and promote the formation of abnormal actin aggregates. The biochemical properties of profilin explain, at least in part, how reduction of the intracellular levels of profilin can elicit both negative and positive effects on actin polymerization (for review, see Machesky and Pollard 1993; Theriot and Michison 1993; Sohn and Goldschmidt-Clermont 1994). Early biochemical studies showed that profilin can bind and sequester $\mathrm{G}$ actin monomers, thus preventing F-actin polymerization and inducing F-actin depolymerization (Carlsson et al. 1977; Pollard and Cooper 1984). More recent studies, however, indicate that profilin can also promote actin polymerization through two different mechanisms. First, under proper conditions, actin-profilin complexes polymerize into filaments more efficiently than G-actin monomers alone, so profilin can lower actin monomer critical concentration (Pantaloni and C arlier 1993). Second, it has been suggested that profilin can promote actin polymerization by catalyzing ADP/ATP exchange on actin. In the presence of excess ATP, profilin would generate ATP-actin, which polymerizes into F-actin faster than ADP-actin (Goldschmidt-Clermont et al. 1992).

The regulatory role of profilin on actin polymerization may also depend on the interaction between profilin and two other ligands of this protein: the polyphosphoinositides and poly-L-proline stretches (for review, see Machesky and Pollard 1993; Theriot and Michison 1993; Sohn and Goldschmidt-Clermont 1994). Polyphosphoinositides such as phosphatidylinositol-4,5 biphosphate (PIP2) can interfere with the formation of profilin-actin complexes (Lassing and Lindberg 1985; Goldschmidt-Clermont et al. 1991). Proteins containing poly-proline stretches such as the product of the cdc12 gene of $\mathrm{S}$. pombe (see above) bind to profilin and contribute to actin polymerization at the contractile ring (Chang et al. 1996, 1997). Finally, the functions of profilin in vivo are also likely to reflect its different effects on actin filaments with barbed ends that are either capped or uncapped (Pantaloni and Carlier 1993). This complex biochemical scenario certainly allows sufficient flexibility for profilin to play diverse biochemical functions in living cells, such as its roles in degradation of the F-actinenriched male fusome and in the assembly of the actomyosin ring that have been documented here. Understanding how all of these potential inputs are integrated to determine profilin activity at particular intracellular locations presents a major challenge for the future.

The actin cytoskeleton and centrosome behavior in spermatocytes

During prophase/prometaphase of both meiotic divisions in chic and dia mutants, and in cytochalasin Btreated testes, the asters fail to associate properly with the nuclear envelope. M oreover, separation of the asters and their movement to opposite poles of the spindle is significantly delayed in all cases, although a bipolar spindle is eventually established. There are several precedents for these findings that alterations of the actin cytoskeleton can affect centrosome behavior. Drugs that interfere with F-actin assembly disrupt normal spindle/ centrosome movements in both budding yeast and nematodes (Hyman and White 1987; Palmer et al . 1992). In S. cerevisiae, a conditional lethal mutation in the actin gene ACT 1 causes spindle misorientation (Pal mer et al. 1992), whereas spindle orientations during the early embryonic divisions of Caenorhabditis el egans are determined by the attachment of mi crotubules to a specific actin containing cortical site (Hyman 1989; Waddle et al . 1994).

The abnormal aster behavior seen in chic and dia mu- 
tants is very similar to that observed previously in tsr mutant spermatocytes (Gunsalus et al. 1995). Previously, we hypothesized that problems in aster localization and migration in tsr mutants could result from either of two mechanisms. First, tsr mutations might disrupt connections between the actin cytoskel eton and the astral microtubules analogous to those involved in embryonic nuclear rotations in C. elegans, although we have no direct evidence for an involvement of specific cortical or perinuclear F-actin foci in spermatocyte aster behavior. The second possi bility is suggested by the presence of large aggregates of F-actin in the vicinity of centrosomes in tsr mutants, which might physically block centrosome movements in mutant spermatocytes. The results presented in this paper show that aster movements are defective in testes treated with cytochal asin or mutant for either chic or dia, even though no actin accumulations are seen at the centrosome in any of these cases. Thus, although we cannot formally exclude that the abnormal aster behavi or seen in tsr mutants is a secondary effect of the unusual actin aggregates associated with the centrosomes, we regard the present findings as strong evidence that the actin cytoskeleton normally plays a direct and crucial role in promoting correct aster positioning and migration during prophase/prometaphase of both meiotic divisions in Drosophila males.

\section{The relationship between profilin and cofilin}

Cofilin accelerates the rate of actin filament turnover in living cells, presumably because of its actin severing and depolymerizing activity, as well as its ability to bind actin monomers (Lappalainen and Drubin 1997; Theriot 1997). Results of our previous investigations on mutants in the tsr gene of Drosophila, which encodes a cofilin homolog, are mostly congruent with this view of cofilin's role. In tsr mutants, the contractile ring forms at the right time and in the correct position. This ring manages to contract, but during telophase, it becomes progressively misshapen and more prominent than in wild type, and eventually fails to disassemble (Gunsalus et al. 1995). This phenotype is clearly anticipated from the decreased rate of actin filament turnover in the contractile ring, expected to accompany cofilin depletion. In contrast, in chic mutants there is a complete failure in contractile ring assembly. Epistasis of chic to tsr is thus easily explained: If there is no contractile ring, it cannot di sassemble improperly. Thus, in terms of these two proteins, actin ring assembly is predominantly determined by the chic profilin, whereas subsequent actin ring disassembly is predominantly regulated by the tsr cofilin. Both of these proteins are nonetheless likely to play at least some role throughout the life history of the contractile ring. For example, the actin ring in tsr mutants does not appear morphologically normal, arguing that actin filament turnover aided by cofilin is important to fine-tune contractile ring structure during its assembly (Gunsalus et al. 1995).

Two other aspects of the epistasis of chic over tsr in double mutants are worthy of brief discussion. First, the double mutants display the same partial failure in fusome disassembly seen in chic mutants alone, yet tsr mutants alone are not defective in fusome disassembly. Why profil in is of greater importance to this process than cofilin is currently unknown. A second intriguing finding is the fact that double-mutant spermatocytes do not contain the large actin aggregates associated with the centrosome seen in tsr mutant spermatocytes. One possibility is that the profilin function is required for the assembly of these F-actin aggregates in the absence of cofilin. Alternatively, it is possible that in double-mutant spermatocytes, the actin that would be used for aggregate formation remains trapped in the fusome remnants.

Interdependence of the central spindle and the contractile ring

Our previous studies established that mutations in KLP3A, a gene encoding a kinesin-like protein, disrupt the formation of the central spindle (Williams et al. 1995). In this paper we present the surprising finding that these same mutations also impair assembly of the actinbased contractile ring. Because kinesins act as microtubule-based motors, it is logical to assume that KLP3A mutations primarily affect the formation of the central spindle and that the absence of the contractile ring is a secondary consequence of this defect. On the other hand, our resul ts in chic and dia mutants, and our observations on cytochal asin B-treated cells, strongly suggest the converse: that problems in contractile ring assembly can secondarily disrupt central spindle formation. Taken together, these results strongly suggest the existence of a cooperative interaction between elements of the actinbased contractile apparatus and the central spindle microtubules. When either of these structures is perturbed, the proper assembly of the other is disrupted.

The idea that spindle microtubules and the actin cytoskel eton may interact with each other during cytokinesis has long been proposed (White and Borisy 1983; Rappaport 1986, 1991), but has only recently recei ved experimental support (Cao and Wang 1996; Fishkind et al. 1996; Wheatley and Wang 1996). The results described in this paper provide further, stronger evidence for such an interaction and raise the question of the underlying molecular mechanisms. The current view is that microtubules can interact with actin filaments through either microtubule-associated proteins (MAPs) (Griffith and Pollard 1978; Sattilaro et al. 1981; Pedrotti et al. 1994), or microtubule-based motor molecules (for review, see Schroer 1994). The microtubule/F-actin interactions involved in contractile ring and central spindle formation arelikely to be mediated by one or more of the numerous proteins that accumulate in the central spindle midzone during late anaphase and telophase (for review, see $\mathrm{M}$ argolis and A ndreassen 1993; Goldberg et al. 1997). These include the so-called passenger proteins (Earnshaw and Bernat 1990) such as the TD60 protein (A ndreassen et al. 1991), the inner centromere protein (IN CEN P; Cooke et al. 1987; Earnshaw and Cooke 1991), and the kinesin- 
like proteins $\mathrm{CHO} 1 / \mathrm{M} \mathrm{KLP1}$, CEN P-E, XKLP1, and chromokinesin (Sellitto and Kuriyama 1988; Yen et al. 1991, 1992; Nislow et al. 1992; Vernos et al. 1995; Wang and Adler 1995), which move from the chromosomes to the spindle midzone. Although impairment of INCENP, CHO1, and XKLP1 functions affect spindle formation and interfere with the completion of cytokinesis, it is not clear whether these effects are accompanied by problems in central spindle assembly ( $\mathrm{N}$ islow et al. 1990; Vernos et al. 1995; Eckley et al. 1997).

In Drosophila, the best candidate at present for mediating interactions between the central spindl e and cortical actin, at least during male meiosis, is the KLP3A kinesin-like protein. This protein could interact di rectly with both the central spindle microtubules and components of the contractile ring. Alternatively, KLP3A could transport to the spindl e midzone molecules that mediate $\mathrm{F}$ actin-microtubule interactions. At the moment, we cannot discriminate between these possibilities, nor we have any information on the proteins that bind to or might be transported by KLP3A. We believe, however, that the isolation and characterization of additional mutations causing cytological phenotypes similar to those of KLP3A, chic, and dia, will eventually provide substantial insight into the mechanisms underlying microtubule-actin interaction during cytokinesis.

\section{Materials and methods}

\section{Drosophila stocks}

The chic alleles $\mathrm{chic}^{\mathrm{R} 1}$, $\operatorname{chic}^{8 \mathrm{~A}}$, chic $^{13 \mathrm{E}}$, and $\mathrm{chic}^{35 \mathrm{~A}}$ were generated through the transposition of single, marked P[lacW] elements (Bier et al. 1989) as outlined by Gatti and Goldberg (1991). M obilization of the P-element insertions associated with these mutant alleles was carried out as described by Gatti and Goldberg (1991). The alleles $\mathrm{Chi}^{37}$ and chic ${ }^{1320}$ (Cooley et al. 1992; Verheyen and Cooley 1994) were the kind gift of Dr. Lynn Cooley (Yale University, New Haven, CT); the deficiencies $\operatorname{Df}(2 \mathrm{~L}) \mathrm{clot} 7$ and $\mathrm{Df}(2 \mathrm{~L}) \mathrm{GpdhA}$ were obtained from Dr. Ross M aclntyre (Cornell University, Ithaca, NY). Mutations in chic and deletions were usually maintained as heterozygotes balanced by the second chromosome balancer $\mathrm{CyO}$. To provide a marker to distinguish between homozygous mutant or heterozygous larvae and pupae, these mutations were also balanced over ST, a translocation between SM6a and the third chromosome balancer TM6B that carries the dominant larval marker Tubby (Tb) (the kind gift of Dr. Antonio Garcia Bellido, Universi dad Autonoma, M adrid, Spain); see al so G atti and Goldberg (1991) for further explanation.

The KLP3A ${ }^{e 4}$ allele has been described previously (Williams et al. 1995). To obtain KLP3A ${ }^{\mathrm{e} 4} / \mathrm{Y}$ male larvae, KLP3A ${ }^{\mathrm{e} 4} / \mathrm{FM} 7$ virgin females were mated to $F M 7 / Y$ males and their progeny were scored for Malpighian tubule coloration (Williams et al. 1995). The $\mathrm{dia}^{1}$ and $\mathrm{dia}^{3}$ alleles (Castrillon and Wasserman 1994) were the kind gift of Dr. Steven Wasserman (University of Texas, Dallas, TX). dia ${ }^{1}$ homozygotes are viable but male sterile, whereas homozygosity for $\mathrm{dia}^{3}$ causes lethality during the early pupal stages. Both mutations were bal anced over In(2LR), $\mathrm{Gla} \mathrm{Bc;}$ the dominant marker Black Cells (Bc) allows recognition of the desired homozygous dia mutant larvae.

The $\mathrm{tsr}^{1}$ mutation has been described by Gunsalus et al. (1995). To construct chic ${ }^{\mathrm{R} 1} \mathrm{tsr}^{1}$ double mutants, $\mathrm{chic}^{\mathrm{R} 1} / \mathrm{tsr}^{1} \mathrm{fe}-$ males were crossed to CyO/Sco males; putative $\mathrm{chic}^{\mathrm{R} 1} \mathrm{tsr}^{1} \mathrm{re}-$ combinant chromosomes were recovered and balanced over CyO. These chromosomes were then tested for complementation with both $\mathrm{chic}^{\mathrm{R} 1}$ and $\mathrm{tsr}^{1}$ to identify double mutants. As a final step, $\mathrm{chic}^{\mathrm{R} 1} \mathrm{tsr}^{1} \mathrm{chromosomes}$ were rebalanced over ST to all ow identification of the double-mutant larvae. All the markers and special chromosomes mentioned above, but not otherwise specified, are described in detail by Lindsley and Zimm (1992).

\section{Identification of P-element insertion sites}

DN A adjacent to the P-el ement insertion sites of the chic alleles chic $^{\mathrm{R1}}$, chic $^{8 \mathrm{~A}}$, chic ${ }^{13 E}$, and $\mathrm{chic}^{35 \mathrm{~A}}$ was cloned by plasmid rescue (Pirrotta 1986). This was possible because the P[lacW] element causing these mutations contains a bacterial origin of replication and a sel ectable marker for ampicillin resistance (Bier et al. 1989). Genomic DNA from adults homozygous for these mutations was prepared, digested with either EcoR 1 or Pstl, and ligated as described by Gunsal us et al. (1995). The ligation mix was transformed directly into XL-1 Blue cells by el ectroporation and desired clones were selected for ampicillin resistance. Double-stranded plasmid DNAs containing parts of the $P$ element and adjacent genomic DNA were sequenced by the dideoxy method (Sanger et al. 1977) by use of Sequenase version 2.0 (U.S. Biochemical Corp.) or the Ladderman kit (Takara Biochemical Inc.), $\left[{ }^{35}\right.$ S]dATP (Amersham Corp.), 6\% Long Ranger (AT Biochem) gels, and sequence-specific primers from the Pelement ends made by the Biotechnology Synthesis and AnaIytical Facility at Cornell University.

\section{Cytology and indirect immunofluorescence}

All techniques for cytological preparations of larval testes, for staining of DNA, microtubules, and F-actin, and for fluorescence microscopy recorded with a cooled charge-coupled device (CCD) have been described previously in detail (Cenci et al. 1994; Gunsalus et al. 1995).

For visualization of microtubules, testes were incubated for 45 min with a 1:50 dilution in PBS of a mouse monoclonal anti- $\alpha$ tubulin antibody (Amersham International). After two 5-min washes in PBS, the slides were incubated for $50 \mathrm{~min}$ with the secondary antibody [sheep anti-mouse IgG, $F(a b)_{2}$ fragment, conjugated with 5(6)-carboxy-fluorescein- $\mathrm{N}$-hydroxysuccinimide ester (FLUOS), (Boehringer) diluted 1:15 in PBS].

For anillin localization, we used a rabbit antiserum raised against amino acids 401-828 of anillin (Field and Alberts 1995), diluted $1: 300$ in PBT (PBS with $0.1 \%$ Triton $\mathrm{X}-100$ ) also containing $1 \%$ BSA. After overnight incubation at $4^{\circ} \mathrm{C}$, the slides were washed twice in PBT and once in PBS, for a total of $15 \mathrm{~min}$. The primary antibody was detected by incubation for $2 \mathrm{hr}$ with FITC-conjugated anti-rabbit IgG (Cappel), diluted 1:15 in PBT.

For $\alpha$-spectrin visualization, we used a rabbit polyclonal antibody (rabbit 675; Byers et al. 1987) diluted 1:100 in PBS. Fixed testes were incubated with the primary antibody overnight at $4^{\circ} \mathrm{C}$ and then washed twice in PBT ( 5 min each) and once in PBS (10 min). They were then incubated with the secondary antibody (FITC-conjugated anti-rabbit IgG, Cappel), diluted 1:15 in PBT.

For profilin localization, fixed testes were incubated overnight in a humid chamber at $4^{\circ} \mathrm{C}$ with an undiluted antiprofilin monoclonal antibody from cell line 6F (Verheyen and Cooley 1994). After three 5 min washes in PBS, the slides were incubated for $50 \mathrm{~min}$ at room temperature with the secondary antibody [sheep anti-mouse IgG, $\mathrm{F}(\mathrm{ab})_{2}$ fragment, conjugated with FLUOS, (Boehringer), diluted 1:15 in PBS]. 
Actin staining was usually performed after immunostaining. 300 units of rhodamine-labeled phalloidin (Molecular Probes) were dissolved in $1.5 \mathrm{ml}$ of methanol. One hundred microliters of this stock solution was vacuum dried and resuspended in 200 $\mu \mathrm{l}$ of PBS. Testis preparations were incubated with $20 \mu$ of this solution for $1 \mathrm{hr}$ and $30 \mathrm{~min}$ at $37^{\circ} \mathrm{C}$.

In all cases, the final staining procedure was treatment with Hoechst 33258. After immunostaining, or immunostaining plus actin staining, testis preparations were rinsed in PBS (10 min), air dried, and stained with Hoechst 33258 according to Cenci et al. (1994).

U nless otherwise specified, all the immunostaining and staining procedures described above were performed at room temperature.

\section{Fluorescence microscopy}

All preparations were examined with a Zeiss Axioplan microscope equipped with an HBO $50 \mathrm{~W}$ mercury lamp for epifluorescence and with a CCD (Photometrics Inc.). Hoechst 33258, FLU OS, and rhodamine fluorescence were detected by use of the 0.1 (BP 365/11, FT 395, LP 397), 10 (BP 450/490, FT 510, LP 515/565), and 15 (BP 546, FT 580, LP 590) Zeiss filter sets, respectively. Gray-scale digital images were collected separately with the IP Lab Spectrum software (Signal Analytics). They were then converted to Photoshop 2.5 format (A dobe Systems), and either used as black and white images or pseudocolored and merged. Final images were printed by a dye sublimation process.

\section{Cytochalasin B treatment}

Larval testes, dissected in saline $(0.7 \% \mathrm{NaCl})$, were incubated with $1 \mu \mathrm{g} / \mathrm{ml}$ of cytochalasin B (Sigma) dissolved in the same saline solution for $2 \mathrm{hr}$ at $25^{\circ} \mathrm{C}$. Testes were then fixed and stained as described above.

\section{Acknowledgments}

We thank Lynn Cooley for her many kindnesses, including the gifts of Drosophila stocks and of anti-chic antibody, and many helpful discussions. We also thank Chris Field and Haifan Lin for providing us with anti-anillin and anti- $\alpha$-spectrin antibodies, and Steven Wasserman for the dia stocks. Further thanks are given to Kris Gunsalus for critical reading of the manuscript. This work was supported by $\mathrm{N}$ ational Institutes of Heal th $\mathrm{Grant}$ 5R01GM 48430 to M.L.G, and by grants to M.G. from Progetto Strategico del Consiglio Nazionale delle Ricerche "Ciclo CelIulare e A poptosi" and from the European Community Human Capital and Mobility Program, contract CHRX-CT 93-0186.

The publication costs of this article were defrayed in part by payment of page charges. This article must therefore be hereby marked "advertisement" in accordance with 18 USC section 1734 solely to indicate this fact.

\section{References}

Andreassen, P.R., D.K. Palmer, M.H. Weiner, and R.L. M argolis. 1991. Telophase disk: A new mammalian mitotic organelle that bisects telophase cells with a possible function in cytokinesis. J. Cell Sci. 99: 523-534.

Aubin, J.E., M. Osborn, and K. Weber. 1981. Inhibition of cyto- kinesis and altered contractile ring morphology induced by cytochalasins in synchronized PtK2 cells. Exp. Cell Res. 136: 63-79.

Bal asubramanian, M.K., B.R. Hirani, J.D. Burke, and K.L. Gould. 1994. The Schizosaccharomyces pombe $\mathrm{cdc}^{+}$gene encodes a profilin essential for cytokinesis. J. Cell Biol. 125: 12891301.

Bier, B.S., H. Vaessin, S. Sheperd, K. Lee, K. McCall, S. Barbel, L. Ackerman, R. Carretto, T. Uemura, E. Grell et al. 1989. Searching for pattern and mutation in Drosophila genome with P-lacZ vector. Genes \& Dev. 3: 1273-1287.

Byers, T.J., R. Dubreuil, D. Branton, D.P. Kiehart, and L.S.B. Goldstein. 1987. Drosophila spectrin. II. Conserved features of the al pha-subunit are reveal ed by analysis of cDN A clones and fusion proteins. J. Cell Biol. 105: 2103-2110.

Cao, L.-G. and Y.-L. Wang. 1996. Signals from the spindle midzone are required for the stimulation of cytokinesis in cultured epithelial cells. Mol. Biol. Cell. 7: 225-232.

Carlsson, M., L.-E. Nystrom, I. Sundkvist, F. Markey, and U. Lindberg. 1977. Actin polymerizability is influenced by profilin, a low molecular weight protein in nonmuscle cells. J. Mol. Biol. 115: 465-483.

Castrillon, D.H. and S.A. Wasserman. 1994. diaphanous is required for cytokinesis in Drosophila and shares domains of similarity with the products of the limb deformity gene. Development 120: 3367-3377.

Cenci, G., S. Bonaccorsi, C. Pisano, F. Verni, and M. Gatti. 1994. Chromatin and microtubule organization during premei otic, meiotic, and early postmeiotic stages of Drosophila melanogaster spermatogenesis. J. Cell Sci. 107: 3521-3534.

Chang, F., A. Woollard, and P. N urse. 1996. Identification and characterization of fission yeast mutants defective in actin ring assembly and placement. J. Cell Sci. 109: 131-142.

- - - 1997. cdc12, a protein required for cytokinesis in fission yeast, is a component of the cell division ring and interacts with profilin. J. Cell Biol. 137: 169-182.

Cooke, C.A., M.M.S. Heck, and W.C. Earnshaw. 1987. The INCEN P antigens: M ovement from the inner centromere to the midbody during mitosis. J. Cell Biol. 105: 1053-2067.

Cooley, L., E. Verheyen, and K. Ayers. 1992. chickadee encodes a profilin required for intercellular transport during Drosophila oogenesis. Cell 69: 173-184.

Cooper, J.A. 1987. Effects of cytochalasin and phalloidin on actin. J. Cell Biol. 105: 1473-1478.

Earnshaw, W.C. and R.L. Bernat. 1990. Chromosomal passengers: Towards an integrated view of mitosis. Chromosoma 100: 139-146.

Earnshaw, W.C. and C.A. Cooke. 1991. Analysis of the distribution of the INCEN Ps throughout mitosis reveals the existence of three distinct substages of metaphase and early events in cleavage furrow formation. J. Cell Sci. 98: 443-461.

Eckley, D.M., A.M. Ainsztein, A.M. M acKay, I.G. Goldberg, and W.C. Earnshaw. 1997. Chromosomal proteins and cytokinesis: Patterns of cleavage furrow formation and inner centromere protein positioning in mitotic heterokaryons and midanaphase cells. J. Cell Biol. 136: 1169-1183.

Edamatsu, M., M. Hirono, and Y. Watanabe. 1992. Tetrahymena profilin is localized in the division furrow. J. Biochem. 112: 637-642.

Field, C. and B.M. Alberts. 1995. A nillin, a contractile ring protein that cycles from the nucleus to the cell cortex. J. Cell Biol. 131: 165-178.

Fishkind, D.J. and Y.-L. Wang. 1995. N ew horizons for cytokinesis. Curr. Opin. Cell Biol. 7: 23-31.

Fishkind, D.J., J.D. Silverman, and Y.-L. Wang. 1996. Function of spindle microtubules in directing cortical movements and 
actin filaments organization in dividing cultured cells. J. Cell Sci. 109: 2041-2051.

Fuller, M.T. 1993. Spermatogenesis. In The development of Drosophila melanogaster. Vol. I. (ed. M. Bate and A.M. Arias), pp. 71-147. Cold Spring Harbor Laboratory Press, Cold Spring Harbor, NY.

Gatti, M. and M.L. Goldberg. 1991. Mutations affecting cell divisions in Drosophila. Methods Cell Biol. 35: 543-586.

Giansanti, M.G., S. Bonaccorsi, B.C. Williams, K. Gunsalus, E.V. Williams, M.L. Goldberg, and M. Gatti. 1996. Genes controlling cytokinesis in Drosophila melanogaster male meiosis. In Proceedings on chromosome segregation and aneuploidy (ed. A. Abbondandolo, B.K. Vig, and R. Roy), pp. 304-316. Istituto N azionale per la Ricerca sul Cancro (IST), Genoa, Italy.

Goldberg, M.L., K. Gunsalus, R.E. Karess, and F. Chang. 1997. Cytokinesis, or breaking up is hard to do. In Mechanics of cell division. (ed. S. Endow and D. Glover). Oxford University Press, London. (In press).

Goldschmidt-Clermont, P.J., J.W. Kim, L.M. Machesky, S.G. Rhee, and T.D. Pollard. 1991. Regulation of phospholipase C-gamma 1 by profilin and tyrosine phosphorylation. Science 251: 1231-1233.

Goldschmidt-Clermont, P.J., M.I. Furman, D. Wachsstock, D. Safer, V.T. N achmias, and T.D. Pollard. 1992. The control of actin nucleotide exchange by thimosin $\beta 4$ and profilin: $A$ potential regulatory mechanism for actin polymerization in cells. Mol. Biol. Cell 3: 1015-1024.

Gonzalez, C., J. Casal, and P. Ripoll. 1989. Relationship between chromosome content and nuclear diameter in early spermatids of Drosophila melanogaster. Genet. Res. 54: 205-212.

Griffith, L. and T.D. Pollard. 1978. Evidence for actin filamentmicrotubule interaction mediated by microtubule-associated proteins. J. Cell Biol. 78: 958-965.

Gunsal us, K.C., S. Bonaccorsi, E. Williams, F. Verni, M. Gatti, and M.L. Goldberg. 1995. Mutations in twinstar, a Drosophila gene encoding a cofilin/ADF homolog, result in defects in centrosome migration and cytokinesis. J. Cell Biol. 131: 1-17.

Haarer, B.K., S.H. Lillie, A.E.M. Adams, V. Magdolen, W. Bandlow, and S.S. Brown. 1990. Purification of profilin from Saccharomyces cerevisiae and analysis of profilin-deficient cells. J. Cell Biol. 110: 105-114.

Hamaguchi, Y. 1975. Microinjection of colchicine into sea urchin eggs. Dev. Growth Differ. 17: 1-117.

Haugwitz, M., A.A. N oegel, J. Karakesisoglou, and M. Schleicher. 1994. Dictyostelium amoebae that lack G-actin-sequestering profilins show defects in F-actin content, cytokinesis, and development. Cell 79: 303-314.

Hime, G.R., J.A. Brill, and M.T. Fuller. 1996. Assembly of ring canals in the male germ line from structural components of the contractile ring. J. Cell Sci. 109: 2779-2788.

Hiramoto, Y. 1956. Cell division without mitotic apparatus in sea urchin eggs. Exp. Cell Res. 11: 630-636.

_-_. 1971. Analysis of cleavage stimulus by means of micromanipulation of sea urchin eggs. Exp. Cell Res. 8: 291-298.

Hyman, A.A. 1989. Centrosome movement in the early divisions of Caenorhabditis el egans: A cortical site determining centrosome position. J. Cell Biol. 109: 1185-1193.

Hyman, A.A. and J.G. White. 1987. Determination of cell division axes in the early embryogenesis of Caenorhabditis elegans. J. Cell Biol. 105: 2123-2135.

Inoue, S. 1990. Dynamics of mitosis and cleavage. Ann. N.Y. Acad. Sci. 582: 1-14.

Kawamura, K. 1977. Microdissection studies on the dividing neuroblast of the grasshopper, with special reference to the mechanism of unequal cytokinesis. Exp. Cell Res. 106: 127137.

Lappalainen, P. and D.G. Drubin. 1997. Cofilin promotes rapid actin filament turnover in vivo. Nature 388: 78-82.

Lassing, I. and U. Lindberg. 1985. Specific interaction between phosphatidylinositol 4,5-biphoshate and profilactin. Nature 314: 472-474.

Lin, H., L. Yue, and A.C. Spradling. 1994. The Drosophila fusome, a germline specific organelle, contains membrane skeletal proteins and functions in cyst formation. Development 120: 947-956.

Lindsley, D.L. and G.G. Zimm. 1992. The genome of Drosophila melanogaster. A cademic Press, San Diego, CA.

Machesky, L.M. and T.D. Pollard. 1993. Profilin as a potential mediator of membrane cytoskeleton communication. Trends Cell Biol. 3: 381-385.

Margolis, R.L. and P.R. Andreassen. 1993. The telophase disc: Its possible role in mammalian cell cleavage. BioEssays 15: 201-207.

Miller, A.L., R.A. Fluck, J.A. M cLaughlin, and L.F. Jaffe. 1993. Calcium buffer injections inhibit cytokinesis in Xenopus eggs. J. Cell Sci. 106: 523-534.

Nislow, C., C. Sellitto, R. Kuriyama, and J.R. M clntosh. 1990. A monoclonal antibody to a mitotic microtubule-associated protein blocks mitotic progression. J. Cell Biol. 111: 511522.

- - - 1992. A plus-end-directed motor enzyme that moves antiparallel microtubules in vitro localizes to the interzone of mitotic spindles. Nature 359: 543-547.

Palmer, R.E. , D.S. Sullivan, T. Huffaker, and D. Koshland. 1992. Role of astral microtubules and actin in spindle orientation and migration in the budding yeast, Saccharomyces cerevisiae. J. Cell Biol. 119: 583-593.

Pantaloni, D. and M.-F. Carlier. 1993. How profilin promotes actin filament assembly in the presence of thymosin $\beta 4$. Cell 75: 1007-1014.

Pedrotti, B., R. Colombo, and K. Islam. 1994. Microtubule associated protein M AP1A is an actin-binding and crosslinking protein. Cell Motil. Cytoskeleton 29: 110-116.

Pirrotta, V. 1986. Cloning Drosophila genes. In Drosophila: A practical approach. (ed. D. B. Roberts), pp. 83-100. IRL Press, Oxford, UK.

Pollard, T.D. and J.A. Cooper. 1984. Quantitative analysis of the effect of Acanthamoeba profilin on actin filament nucleation and elongation. Biochemistry 23: 6631-6641.

Rappaport, R. 1961. Experiments concerning the cleavage stimulus in sand dollar eggs. J. Exp. Zool. 148: 81-89.

-_- 1985. Repeated furrow formation from a single mitotic apparatus in cylindrical sand dollar eggs. J. Exp. Zool. 234: 167-171.

-_- 1986. Establishment of the mechanism of cytokinesis in animal cells. Int. Rev. Cytol. 105: 245-281.

_-_. 1991. Cytokinesis. In O ogenesis, spermatogenesis and reproduction, comparative physiology. (ed. K.H. Kinn), vol. 10. pp. 1-36. Karger, Basel, Switzerland.

Rappaport, R. and B.N. Rappaport. 1974. Establisment of cleavage furrows by the mitotic spindle. J. Exp. Zool. 189: 189196.

- - . 1983. Cytokinesis: Effects of blocks between the mitotic apparatus and the surface on the furrow establishment in flattened echinoderm eggs. J. Exp. Zool. 227: 213-227.

Robinson, D.N . and L. Cooley. 1996. Stable intercellular bridges in devel opment: The cytoskel eton lining the tunnel. Trends Cell Biol. 6: 474-479.

Sanger, F., S. N iecklen, and I.R. Coulson. 1977. DN A sequenc- 


\section{Giansanti et al.}

ing with chain-terminating inhibitors. Proc. Natl. Acad. Sci. 74: 5463-5467.

Satterwhite, L.L. and T.D. Pollard. 1992. Cytokinesis. Curr. Opin. Cell Biol. 4: 43-52.

Sattilaro, R.F., W.L. Dentler, and E.L. LeCluyse. 1981. Microtubule-associated proteins (MAPs) and organization of actin filaments in vitro. J. Cell Biol. 90: 467-473.

Sellitto, C. and R. Kuriyama. 1988. Distribution of a matrix component of the midbody during the cell cycle in chinese hamster ovary cells. J. Cell Biol. 106: 431-439.

Schroer, T.A. 1994. N ew insights into the interaction of cytoplasmic dynein with actin related protein, Arpl. J. Cell Biol. 127: 1-4.

Sohn, R.H. and P.J. Goldschmidt-Clermont. 1994. Profilin: At the crossroads of signal transduction and the actin cytoskeleton. BioEssays 16: 465-470.

Tates, A.D. 1971. Cytodifferentiation during spermatogenesis in Drosophila melanogaster: An electron microscope study. Ph.D. Thesis. Rijksuniversiteit, Leiden, The N etherlands.

Theriot, J.A. 1997. Accelerating on a treadmill: ADF/cofilin promotes rapid actin filament turnover in the dynamic cytoskeleton. J. Cell Biol. 136: 1165-1168.

Theriot, J.A. and T. Michison 1993. The three faces of profilin. Cell 75: 835-838.

Verheyen, E.M . and L. Cooley. 1994. Profilin mutations disrupt multiple actin-dependent processes during Drosophila development. Development 120: 717-728.

Vernos, I., J. Raats, T. Hirano, J. Heasman, E. Karsenti, and C. Wylie. 1995. Xklp1, a chromosomal Xenopus kinesin-like protein essential for spindle organization and chromosome positioning. Cell 81: 117-127.

Waddle, J.A., J.A. Cooper, and R.H. Waterson. 1994. Transient localized accumulation of actin in Caenorhabditis elegans blastomeres with oriented asymmetric divisions. Development 120: 2317-2328.

Wang, S.-Z. and R. Adler. 1995. Chromokinesin: A DNA-binding, kinesin-like nuclear protein. J. Cell Biol. 128: 761-768.

Wheatley, S.P. and Y.-L. Wang. 1996. Midzone microtubule bundles are continuously required for cytokinesis in cultured epithelial cells. J. Cell Biol. 135: 981-989.

White, J.G. and G.G. Borisy. 1983. On the mechanism of cytokinesis in animal cells. J. Theor. Biol. 101: 289-316.

Williams, B.C., M.F. Riedy, E.V. Williams, M. Gatti, and M.L. Goldberg. 1995. The Drosophila kinesin-like protein KLP3A is a midbody component required for central spindle assembly and initiation of cytokinesis. J. Cell Biol. 129: 709-723.

Yen, T.J., D.A. Compton, D. Wise, R.P. Zinkowski, B.R. Brinkley, W.C. Earnshaw, and D.W. Cleveland. 1991. CEN P-E, a novel human centromere-associated protein required for progression from metaphase to anaphase. EMBO J. 10: 12451254.

Yen, T.J., G. Li, B.T. Schaar, I. Szilak, and D.W. Cleveland. 1992. CEN P-E is a putative kinetochore motor that accumulates just before mitosis. Nature 359: 336-339. 


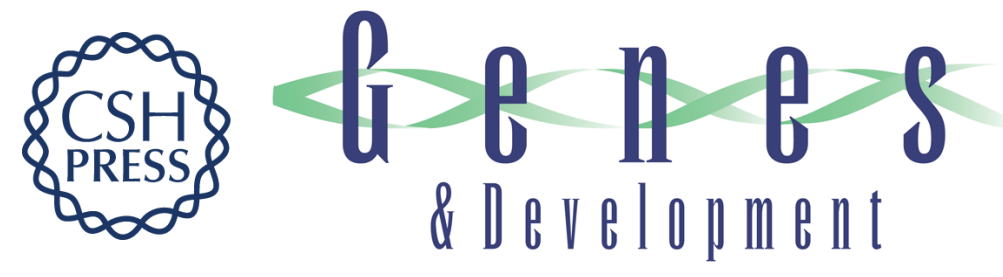

\section{Cooperative interactions between the central spindle and the contractile ring during Drosophilacytokinesis}

Maria Grazia Giansanti, Silvia Bonaccorsi, Byron Williams, et al.

Genes Dev. 1998, 12:

References This article cites 71 articles, 36 of which can be accessed free at:

http://genesdev.cshlp.org/content/12/3/396.full.html\#ref-list-1

License

Email Alerting Receive free email alerts when new articles cite this article - sign up in the box at the top Service right corner of the article or click here.

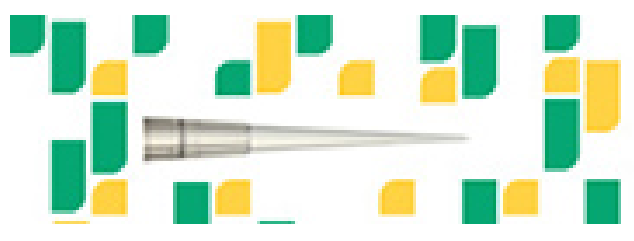

Focused on your science. 